\title{
Analysis of Industrial Economic Growth and Environmental Pollution in Tianjin Based on Tapio Decoupling Model
}

\author{
Zening Liu ${ }^{1}$, Yingchun Wang ${ }^{2}$ \\ ${ }^{1}$ School of management, Tianjin University of Technology, Tianjin 300384, China, 314652367@qq.com \\ ${ }^{2}$ School of management, Tianjin University of Technology, Tianjin 300384, China, ycwang@sina.com
}

\begin{abstract}
In order to accelerate the construction of a resource-saving and environmentally-friendly industrial ecosystem, this paper uses the Tapio decoupling analysis model to calculate the decoupling index of Tianjin's industrial economic growth and the major environmental pollutants of the industry from 2005 to 2015 and analyze the decoupling status. The results show that the decoupling state of Tianjin's economic growth and environmental pollution from 2005 to 2015 is generally in a strong positive decoupling and a weak growth decoupling, but the decoupling state of some environmental pollution factors has temporarily deteriorated. The relationship between industrial economic growth and industrial pollutant emissions has eased in the 12th Five-Year Plan.
\end{abstract}

\section{Introduction}

The concept of green development regards environmental protection as the prerequisite and endogenous driving force for economic and social development. It emphasizes that the economy and the environment are mutually coordinated and maintained in harmony as a whole. While improving the ability of human sustainable development, it also meets the growing environmental needs. At this stage, the contradiction between economic construction and the ecological environment is becoming increasingly prominent. A series of problems such as resource scarcity, environmental pollution, and ecological imbalances have become bottlenecks that restrict China's economic and social development ${ }^{[1]}$.

The use of decoupling tools to study the relationship among regional economic growth and pollution emissions, energy consumption, and land expansion has been carried out ${ }^{[2-6]}$. This paper uses decoupling analysis tool to evaluate the decoupling status of Tianjin's economic growth and environmental pollutants from 2005 to 2015, and proposes rmeasures to achieve decoupling of economic growth and environmental pollution. It is hoped that these measures can provide reference for the green development of Tianjin's industry.

\section{Decoupling analysis tool}

Decoupling means that the interrelationship between two or more physical quantities with a related relationship no longer exists. In the field of resources and environment, decoupling is generally used to describe the process of breaking the link between environmental damage and economic development ${ }^{[7]}$. The professor of Finnish Future Research Center proposed decoupling elasticity, introduced the concept of elasticity to construct decoupling indicators, and perfected the decoupling model ${ }^{[8]}$. The Tapio decoupling model is an elastic analysis method based on the time scale as an extension of the OECD decoupling model. The advantage is that it overcomes the difficulty of selecting the base period of the OECD decoupling model and improves the objectivity and accuracy of the decoupling analysis. The Tapio decoupling model formula is:

$$
R_{j}=\Delta D / \Delta G=\frac{\left(D_{j}-D_{i}\right) / D_{i}}{\left(G_{j}-G_{i}\right) / G_{i}}
$$

Among them, $R_{j}$ is the decoupling index of economic growth and pollution emissions in the $\mathrm{j}$-th year. $\Delta D$ is the rate of change of pollution emissions. $\Delta G$ is the rate of change of economic growth. $D_{j}$ and $D_{i}$ are the pollution emissions at the end of the study period and the beginning of the year, respectively. $G_{j}$ and $G_{i}$ are the economy at the end of the study period and the beginning of the year, respectively.

According to the meaning of the eight states defined by Tapio decoupling, the decoupling states of economic growth and environmental pollution are shown in Table 1.

Table 1. Decoupling states of economic growth and environmental pollution

\begin{tabular}{|c|c|c|c|}
\hline Decoupled state & $\Delta G$ & $\Delta D$ & $R$ \\
\hline $\begin{array}{c}\text { Strong positive } \\
\text { decoupling }\end{array}$ & $>0$ & $<0$ & $<0$ \\
\hline $\begin{array}{c}\text { Weak decoupling of } \\
\text { growth }\end{array}$ & $>0$ & $>0$ & $0 \sim 0.8$ \\
\hline $\begin{array}{c}\text { Decay strong } \\
\text { connection }\end{array}$ & $<0$ & $<0$ & $>1.2$ \\
\hline Growth connection & $>0$ & $>0$ & $0.8 \sim 1.2$ \\
\hline Decay connection & $<0$ & $<0$ & $0.8 \sim 1.2$ \\
\hline
\end{tabular}




\begin{tabular}{|c|c|c|c|}
\hline $\begin{array}{c}\text { Growth strong } \\
\text { connection }\end{array}$ & $>0$ & $>0$ & $>1.2$ \\
\hline Weak decoupling & $<0$ & $<0$ & $0 \sim 0.8$ \\
\hline $\begin{array}{c}\text { Strong negative } \\
\text { decoupling }\end{array}$ & $<0$ & $>0$ & $<0$ \\
\hline
\end{tabular}

\section{Decoupling Empirical Analysis}

\subsection{Data sources}

The research data are all from Tianjin Statistical Yearbook. In the study, the economic growth factor used industrial added value to avoid information distortion of the decoupling state of pollutants caused by economic growth being amplified. The indicators that support economic growth and affect environmental pollution are selected from industrial energy consumption, and the environmental pollution factors are selected from industrial wastewater discharge, industrial chemical oxygen demand (COD) discharge, industrial waste gas discharge, industrial sulfur dioxide discharge, and industrial solid waste production. Because the industrial chemical oxygen demand emissions were not counted before 2006, the industrial chemical oxygen demand emissions in 2005 were missing. Since 2015, the statistical caliber of industrial waste gas, waste water and other indicators has changed, so the research period is selected from 2005 to 2015 .

\subsection{Results and analysis}

The statistical data of Tianjin's economic growth and environmental pollution since 2005 is used. Among them, Tianjin's industrial GDP index $(1978=100)$ is shown in Figure 1. Calculate the decoupling indices of economic growth relative to industrial wastewater discharge, industrial chemical oxygen demand discharge, industrial waste gas discharge, industrial sulfur dioxide discharge, and industrial solid waste production according to the formula. See Table 2, Table 3, Figure 2, and Figure 3 and Figure 4.

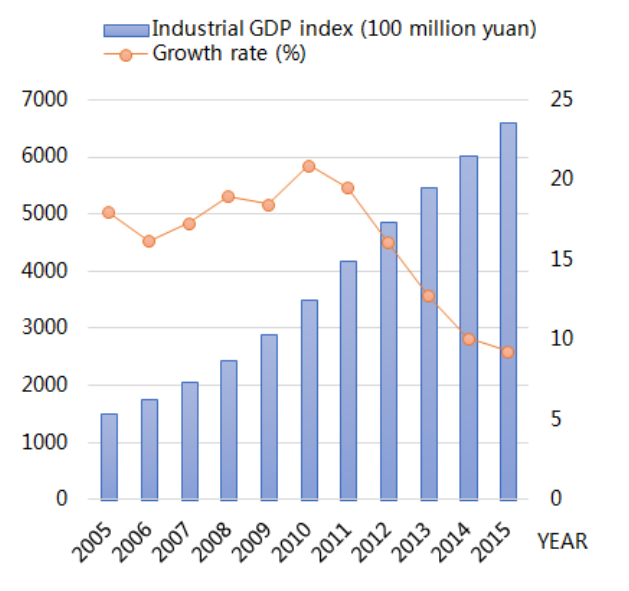

Fig. 1. Industrial GDP index and growth rate from 2005 to 2015
Table 2. Decoupling Index from 2005 to 2015

\begin{tabular}{|c|c|c|c|}
\hline Year & $\begin{array}{c}\text { Energy } \\
\text { consumption }\end{array}$ & $\begin{array}{c}\text { Waste } \\
\text { water }\end{array}$ & COD \\
\hline 2005 & 1.0000 & 1.0000 & - \\
\hline 2006 & 0.7794 & -1.4574 & 1.0000 \\
\hline 2007 & 0.4877 & -0.3859 & -0.9713 \\
\hline 2008 & 0.3610 & -0.2457 & -0.4971 \\
\hline 2009 & 0.4345 & -0.2650 & -0.8422 \\
\hline 2010 & 0.9851 & 0.0586 & -0.2550 \\
\hline 2011 & 0.7114 & 0.0302 & 0.4792 \\
\hline 2012 & 0.4562 & -0.2127 & 0.5898 \\
\hline 2013 & 0.5933 & -0.1743 & -0.1138 \\
\hline 2014 & 0.2578 & 0.1690 & 0.7758 \\
\hline 2015 & -0.1782 & -0.0215 & -0.0803 \\
\hline
\end{tabular}

Table 3. Decoupling Index from 2005 to 2015

\begin{tabular}{|c|c|c|c|}
\hline Year & Exhaust gas & $\begin{array}{c}\text { Sulfur } \\
\text { dioxide }\end{array}$ & Solid Waste \\
\hline 2005 & 1.0000 & 1.0000 & 1.0000 \\
\hline 2006 & 2.5615 & -0.1980 & 0.9288 \\
\hline 2007 & -0.8931 & -0.1866 & 0.4788 \\
\hline 2008 & 0.4769 & -0.3511 & 0.3009 \\
\hline 2009 & -0.0198 & -0.9487 & 0.1352 \\
\hline 2010 & 1.3618 & 1.2347 & 1.0919 \\
\hline 2011 & 0.8227 & 0.1008 & -0.2754 \\
\hline 2012 & 0.0787 & -0.1796 & 0.2432 \\
\hline 2013 & -0.8265 & -0.2798 & -0.9721 \\
\hline 2014 & 0.8823 & -0.5908 & 0.8766 \\
\hline 2015 & -0.5438 & -2.2449 & -1.2318 \\
\hline
\end{tabular}

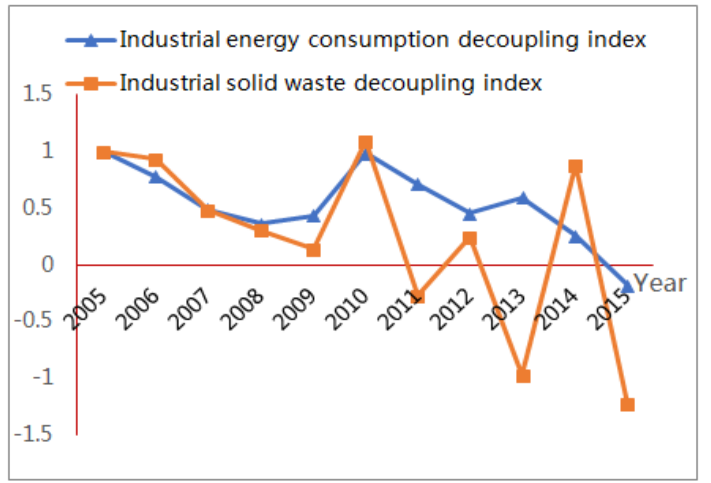

Fig. 2. Decoupling index of industrial economic growth with energy consumption and solid waste

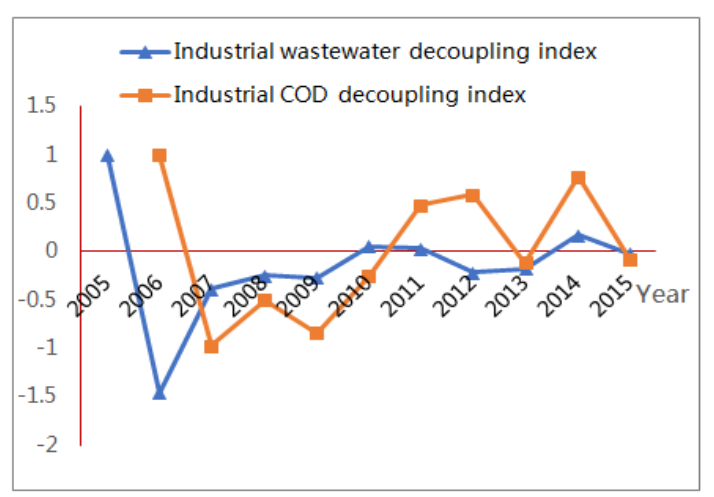

Fig. 3. Decoupling index of industrial economic growth with wastewater and COD 


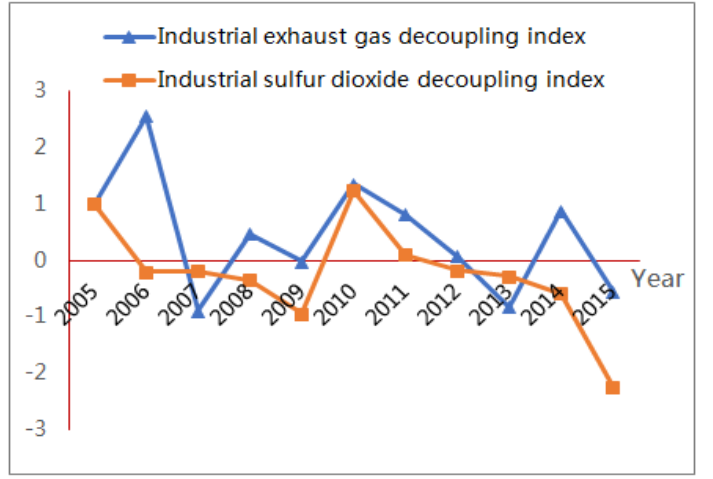

Fig. 4. Decoupling index of Industrial economic growth with exhaust gas and sulfur dioxide

From Table 2, Figure 2, Figure 3 and Figure 4, it can be seen that the decoupling relationship between industrial economic growth and environmental pollution in Tianjin has only four scenarios: strong positive decoupling, weak growth decoupling, growth connection, and growth strong connection. It indicates that Tianjin's industrial economic growth has been in a state of continuous growth since 2005, with an average annual growth rate of $16.0 \%$, and there has been no recession, showing a good development momentum of the industrial economy.

Industrial energy consumption is generally in a weak decoupling of growth. It was in a strong positive decoupling in 2015, but there was a growth connection in 2010. It shows that industrial energy supports the industrial economic growth obviously. Industrial wastewater discharge and industrial chemical oxygen demand are generally in a strong positive decoupling and weak decoupling growth. It shows that industrial wastewater and industrial chemical oxygen demand are basically decoupled from industrial economic growth. Industrial exhaust emissions were in strong decoupling and weak decoupling in the years with more than $50 \%$ of growth, but there was a growth connection in 2011 and 2014, and a strong growth connection in 2006 and 2010. This shows that the state of decoupling of industrial exhaust emissions is very unstable. Industrial sulfur dioxide emissions are in a strong positive decoupling and a weak growth decoupling, and in 2010 and 2011 were in a strong growth delink and weak decoupling, respectively. This shows that the national energy conservation and emission reduction policies are effective. The amount of industrial solid waste production is generally in a strong decoupling and weak growth decoupling, but growth links appeared in 2006, 2010 and 2014. This shows that the production of industrial solid waste has been better controlled.

2006 to 2010 is the eleventh five-year plan, and 2011 to 2015 is the twelfth five-year plan. The relationship between industrial economic growth and industrial pollutant emissions has eased in the 12th Five-Year Plan. This may be because Tianjin responded to national policies and took a new road to industrialization during the eleventh five-year plan period. The industrial economy grew rapidly and pollution emissions were high. During the twelfth five-year plan period, Tianjin's industry took a green development path, built a resourcesaving and environment-friendly society, and effectively controlled the discharge of industrial pollutants.

\section{Questions and suggestions}

\subsection{Accelerate the green transformation of the industry}

The growth of the industrial economy is accompanied by environmental damage. The most effective solution to this problem is to accelerate the industrial green transformation. Implement an innovation-driven strategy, focus on developing emerging industries, and form strategic emerging industry market size advantages and technology leadership advantages. Vigorously develop a green and low-carbon economy, and gradually build an industrial ecosystem characterized by low carbon emissions.

\subsection{Implementing a sustainable energy development strategy}

From the above analysis, we can see that the development of the industrial economy depends to a large extent on energy consumption. This requires implementing a correct and effective strategy for sustainable energy development. On the one hand, increase the efficiency of energy conversion and get the maximum output with the smallest input. On the other hand, establish the concept of giving priority to energy conservation and invest heavily in the use of clean and renewable energy.

\subsection{Attaching importance to pollutant recycling}

Aiming at the discharge of industrial pollutants, pollution treatment methods should be innovated. In the treatment of pollutants, the secondary utilization of the resources available in the pollutants is used to maximize the recycling rate of resources and the comprehensive level of waste ${ }^{[9]}$. The realization of more efficient secondary utilization of related wastes requires researchers to conduct in-depth research on recycling technologies. By improving and optimizing recycling technology, the recycling capacity of available resources will be improved.

\section{Conclusion}

This paper uses the decoupling analysis tool to calculate the decoupling index of Tianjin's industrial economic growth and the major environmental pollutants of the industry from 2005 to 2015 . The results show that since 2005, Tianjin's industrial economic growth has basically been decoupled from industrial wastewater, industrial chemical oxygen demand, and industrial sulfur dioxide emissions. However, it has not yet been completely decoupled from industrial energy consumption, industrial exhaust emissions, and industrial solid waste generation. 
The causes of environmental pollution are complex and changeable. This article only analyzes the decoupling of industrial economic growth from major industrial pollutants. In future research, it is necessary to consider the various factors that cause environmental pollution, in order to more scientifically measure the decoupling state and relationship between economic growth and environmental pollution, and provide a reference for the green development path.

\section{References}

1. Liu Yang. Ecological culture and the construction of a "two-oriented society" [J]. Literature and History Expo (Theory), 2012 (05): 31-33.

2. Yang Lizhu, Wang Shijin. Decoupling of Industrial Carbon Emissions in Jiangsu Province and Analysis of Influencing Factors [J]. China Collective Economy, 2020 (02): 17-18.

3. Hu Lina, Hu Haiyang. A Study on the Relationship between Carbon Emissions and Economic Growth in Tibet Tourism Based on Decoupling Theory [J]. Journal of Tibet University (Social Science Edition), 2019, 34 (04): 185-192 + 208.

4. Cui Muhua. Decoupling Analysis and Scenario Planning of Resource Consumption, Pollution
Emissions and Economic Growth in Anhui Province [J]. Journal of Changjiang Normal University, 2018, 34 (06): 18-26 + 119 .

5. Guo Chenglong. Decoupling Analysis of Economic Growth and Energy Consumption in Jiangsu Province [J]. China Collective Economy, 2017 (33): 19-21.

6. Li Dan, Liu Ruoli. Research on the relationship between carbon emissions and economic growth in Liaoning Province based on the decoupling theory $[J]$. Strait Science and Technology and Industry, 2017 (10): 31-33.

7. Yu Fawen. An empirical study on the decoupling relationship between economic development and resources and environment [J]. Journal of Inner Mongolia University of Finance and Economics, 2009 (03): 29-34. Industry, 2017 (10): 31-33.

8. Petri Tapio. Towards a theory of decoupling: degrees of decoupling in the EU and the case of road traffic in Finland between 1970 and 2001[J]. Transport Policy,2005,12(2).

9. Song Qianqian. Status of industrial solid waste and environmental protection measures $[\mathrm{J}]$. Theoretical Research on Urban Construction (Electronic Edition), 2019 (03): 15 